Revista de Filología Románica

ISSN: 0212-999X

http://dx.doi.org/10.5209/RFRM.63504

\title{
Raíces prerromanas en falsos zootopónimos de la provincia de Cáceres ${ }^{1}$
}

\author{
Manuel Mañas Núñez²
}

Recibido: 22 de enero de 2018 / Aceptado: 12 de septiembre de 2018

Resumen. El presente trabajo tiene como punto de partida el análisis lingüístico de diversos topónimos, en su mayoría pueblos de la provincia de Cáceres, cuyos nombres aparentemente se presentan como zootopónimos diáfanos, pero cuya auténtica etimología es más oscura y remonta a raíces muy antiguas, todas prerromanas, que no tienen ninguna relación con los animales que supuestamente dan nombre a estas localidades. Al hilo de este análisis etimológico, el estudio traspasará las fronteras cacereñas y se ampliará a otros topónimos semejantes, tanto españoles como europeos, especialmente franceses.

Palabras claves: Toponimia prerromana; zoonimia; Cáceres; España; Europa.

\section{[en] Pre-roman roots of false zootoponyms in the province of Cáceres}

Summary. This paper focuses on the linguistic analysis of various place names, mostly villages in the province of Cáceres, whose names apparently appear as obvious zootoponyms, but whose authentic etymology is obscurer and dates back to very ancient roots, all pre-Roman, that are not related to the animals that supposedly give names to these towns. Following this etymological analysis, the study will go beyond the province of Cáceres and will be extended to other similar place names, both Spanish and European, especially French.

Keywords: Pre-roman Toponymy; Zootoponymy; Cáceres; Spain, Europe.

Sumario: 1. Introducción; 2. Las moscas; 3. Los puercos; 4. Los toros y las vacas; 5. Las cabras; 6. Los gatos; 7. Los lobos; 8. Conclusiones. 9. Referencias bibliográficas.

Cómo citar: Mañas Núñez, M. (2019). Raíces prerromanas en falsos zootopónimos de la provincia de Cáceres, en Revista de Filología Románica 36, 29-44.

\section{Introducción}

Los topónimos, cuando se crearon, pertenecían al léxico común de sus creadores y tenían un significado concreto que, normalmente, tenía que ver con las cualidades geomorfológicas del lugar al que se aplicaban, aludiendo a las características particulares de los accidentes geográficos a los que se quería poner nombre o a los ele-

\footnotetext{
$1 \quad$ Este artículo se inscribe en la línea del Proyecto de Investigación FFI2017-82101-P, dirigido por el Dr. D. Luis Merino Jerez y subvencionado por el Ministerio de Economía, Industria y Competitividad.

2 Departamento de Ciencias de la Antigüedad - Universidad de Extremadura mmanas@unex.es
} 
mentos distintivos de los ríos y arroyos que se pretendía identificar. Pero estamos hablando de pueblos muy antiguos, unos no indoeuropeos, como los iberos, vascones o aquitanos, y otros indoeuropeos, como, por ejemplo, los lusitanos, vetones y celtas.

El caso es que, con el paso del tiempo, los nombres que estos pueblos primitivos pusieron a los terrenos y a las aguas atendiendo a sus características particulares se han ido desconectando de las realidades nombradas. El hablante fue perdiendo la conexión entre el significante y el significado y tales topónimos ya no le decían nada, quedando así como fósiles vivos, oscuros, opacos e incomprensibles. Y, como esos nombres le resultaban indescifrables, los fue cambiando y deformando a lo largo del tiempo hasta que de nombres propios que eran los convirtió en nombres comunes. Desde las primigenias lenguas no indoeuropeas que pudieron hablarse en la península ibérica, a lo largo de miles de años unas lenguas han sido sustituidas por otras y ha habido también distintas evoluciones fonéticas y semánticas, porque el hablante intenta siempre encontrar un significado a los nombres que pronuncia.

El resultado, pues, es que muchos de los topónimos que vamos a estudiar son aparentemente claros y dicen cosas, pero dicen cosas absurdas, que nada tienen que ver con los lugares a los que están haciendo referencia. Si son topónimos muy antiguos, algunos incluso de origen preindoeuropeo, no pueden llevar nombres que actualmente tienen un significado claro en nuestro español del siglo XXI. Llamar a unas elevaciones o montes Sierra de la Mosca tiene sentido aparente, pero, en el fondo, es absurdo, pues el insecto "mosca" no es característico de ningún tipo de sierra. Designar a una corriente de agua Arroyo del Puerco parece decirnos algo coherente y específico, pero en realidad es algo poco significativo y muy genérico, pues el cerdo o el jabalí son comunes a todos los cursos de agua, como el resto de fauna que va allí a beber o a revolcarse. Dar a un pueblo o a un río una denominación que contenga nombres como Toro, Vaca, Cabra o Gato o algunos de sus derivados puede ser que nos haga creer que comprendemos lo que estamos diciendo, pero en verdad lo que creemos entender no guarda relación alguna con lo que los primeros hablantes quisieron expresar cuando, hace miles de años, pusieron un nombre similar a esa población o a ese río concretos. Si los topónimos que vamos a estudiar nos parecen, a primera vista, transparentes, es porque el hablante los ha ido cambiando con el paso del tiempo y los ha deformado, acudiendo a la etimología popular, para que digan cosas comprensibles en nuestra habla actual, aunque en realidad el significado aparente será muchas veces subjetivo, incoherente y hasta disparatado.

Con el paso de los distintos pueblos y lenguas, como decimos, con la evolución fonética y semántica, con la etimología popular y también con la ayuda de los copistas, que no siempre transcriben correctamente, muchos topónimos se han deformado arbitrariamente y su auténtico significado nada tiene que ver con el sentido que actualmente se le da. Ello ha motivado errores curiosos en fechas recientes, como, por ejemplo, a la hora de establecer los escudos heráldicos de los pueblos: al escudo de la localidad de Cabrero (Cáceres) se le han insertado cinco cabras, aunque el significado primigenio del topónimo no tiene nada que ver con las cabras; al escudo de Tornavacas (Cáceres) se le han pintado dos vacas con antorchas en los cuernos, aunque eso tiene que ver con la fábula y no con la realidad del topónimo; el escudo de Gata (Cáceres) lleva una gata muy femenina con un bonito lazo al cuello, pero el nombre de esta localidad no guarda relación alguna con los felinos.

Según todo lo dicho, el presente trabajo tiene como punto de partida el análisis lingüístico de diversos topónimos, en su mayoría pueblos de la provincia de Cáce- 
res, cuyos nombres aparentemente se presentan como zootopónimos diáfanos, pero cuya auténtica etimología es más oscura y remonta a raíces muy antiguas, todas prerromanas, que no tienen ninguna relación con los animales que supuestamente dan nombre a estas localidades. Al hilo de este análisis etimológico, el estudio traspasará las fronteras cacereñas y se ampliará a otros topónimos semejantes, tanto españoles como europeos.

\section{Las moscas}

Hay en la toponimia española numerosas elevaciones, algunas de considerable altitud, que llevan el nombre Mosca o alguno de sus derivados, como, por ejemplo, el Pico Escobella, Altet de la Mosca o Pico de la Mosca (693 m., Alicante); la Pena Mosca (1081 m., Asturias); el Collado y Laguna de la Mosca, a 2990 m., al pie de la pared norte del Mulhacén (Granada); el Collado la Mosca (1399 m.), en el desfiladero de los Beyos, en la Cordillera Cantábrica, una gran pared, lisa y vertical; el Pico del Mosquito (2249 m.), en la Sierra de Gredos abulense, muy cerca de Extremadura; y también un Pico Mosquito en las montañas leonesas; o los Cerros del Mosquito, con 1965 m., en la Sierra de Cabras (Albacete). También en la ciudad de Cáceres tenemos una Sierra de la Mosca, cuyo topónimo intentaremos explicar y conectar con otros similares de la geografía española y europea.

La Sierra de la Mosca, ubicada en los alrededores inmediatos de Cáceres, está formada por un grupo de pequeñas sierras que, de forma oval y con unos siete kilómetros de longitud, se alarga en dirección sureste desde el casco histórico de la ciudad, destacando como una pequeña elevación sobre la amplia penillanura cacereña y constituyendo el punto más elevado de la comarca de los Llanos de Cáceres. Es como un bosque aislado y elevado que se encuentra rodeado de una extensa llanura fuertemente desarbolada dedicada a pastos y al cultivo. Realmente, se puede decir que la ciudad está integrada en dicha sierra, pues el recinto amurallado de Cáceres, la llamada Ciudad Antigua, está situada sobre una suave loma que forma parte de uno de los extremos de la mencionada Sierra de la Mosca. En el extremo opuesto se encuentra El Risco de Sierra de Fuentes, en la parte más elevada de la sierra (664 metros), un castro situado en el extremo sur de la Sierra de la Mosca, ubicado en un lugar estratégico, por observarse desde aquí la amplia penillanura cacereño-trujillana y ofrecer a sus pobladores una extraordinaria defensa natural. En este lugar los restos arqueológicos (apareció un escoplo) denuncian que hubo un asentamiento del Bronce Final (Martín 1999: 35-37).

La semántica del topónimo, como es obvio, siempre ha sido relacionada por la población cacereña con el insecto mosca, en el sentido de que es una sierra donde hay mucha mosca. Pero parece evidente que el filólogo y el etimologista no pueden admitir esta teoría. No sólo hay una Sierra de la Mosca en Cáceres, sino que también existe en el término de Selva, en la Montaña de Mallorca, un pueblo que se llama actualmente Moscari y que en el Repartimiento medieval aparece con la forma Moscaritx (con el sufijo mozárabe -itx). Aduce Galmés (1996: 16) que, como en las montañas de Selva se producen espontáneamente flores con olor de "almizcle", le parece claro que Moscari deriva del latín muscus, "almizcle", en relación con otros términos derivados de la misma raíz, como nuez "moscada", "moscatel", pera 
"mosqueruela" o rosa "mosqueta". Asimismo, de este término latino muscus derivarían otros topónimos similares, como Mosqueda (Badajoz), Mosqueiro (Orense, Pontevedra), Mosqueruela (Teruel), Mosquera (Navarra) y La Mosquera (Andorra). En todos estos casos, pues, estaríamos en opinión de Galmés ante fitónimos relacionados con el almizcle.

Es posible, a nuestro parecer, que deriven todos ellos del término latino muscus, pero no con el significado de "almizcle", sino con el significado de "musgo", que es la evolución normal del término latino al español. A todos los topónimos citados por Galmés, podríamos añadir el monte Moscadero (de 1134 metros, entre Burgos y Álava), Moscador de Treviño (Burgos), Moscán (Lugo), Moscardón (Teruel), Moscas del Páramo (León), Moscolux (Almería) y Moscoso (Pontevedra). Son todos topónimos ubicados en terrenos serranos y montañosos (salvo Moscas del Páramo), con lo que muy bien podrían proceder del término latino muscus, "musgo", pues en estos lugares, sobre todo en las zonas umbrías, habrá abundancia de musgo. Es el argumento que se ha sostenido, por ejemplo, para el despoblado de Mosquera, al norte de Fontellas (Navarra), aduciendo Canto (1999: 350) que el topónimo no debe venir de musca, "mosca, lugar de moscas", sino quizás de "musgo" (muscus, muscaria) o de una especie de ave muscicápida, la muscaria, llamada actualmente "moscareta" o "papamoscas", que se alimenta de insectos.

Lo que parece claro es que, como arguye Galmés (1987: 37), los animales, y menos los insectos tan comunes e insignificantes como las moscas, no sirven por lo general para definir rasgos particulares y peculiares de la toponimia. En Asturias, por ejemplo, tenemos topónimos como La Mosqueira (Taramundi), La Mosquitera (Langreo) o Mosquitera (Siero), donde moscas y mosquitos no tienen nada que ver con el significado de estos étimos, pues son insectos que abundan en todas partes y que no caracterizan ningún lugar determinado, menos aún terrenos o parajes ubicados en zonas elevadas, montañosas y rocosas. Por ello, otros etimologistas, como Corominas, creen que el topónimo catalán La Mosquera alude a un paraje boscoso y fresco, una especie de locus amoenus, donde sesteaba el ganado para protegerse de las moscas. También García Arias (2010: 392) cree que El Moscadoriu (Teberga) hay que relacionarlo con moscar, "correr el ganando o espantarse por causa del calor y porque le pica la mosca" y "situarse en lugar fresco o a la sombra para evitar la picadura de las moscas y el calor", siempre remontándose etimológicamente al latín muscam. Otros, como García Martínez (1993: 128), a propósito del topónimo Moscas del Páramo (León), apoyando su tesis en que el pueblo está en un terreno llano, yermo, raso y desabrigado, piensa que Moscas debe relacionarse con muesca y con el verbo dialectal moscar, recogido en el D.R.A.E. con el significado de "hacer una muesca" y derivado del latín vulgar mossicare, que procede del latín morsicare, "mordiscar". En este sentido, el topónimo aludiría a "muescas o hendiduras en el terreno" y sería un orónimo. Y, también en León, existen topónimos menores como La Muesca, Collado de la Muesca o Cáscaros de la Muezca, igualmente en zonas elevadas y rocosas de montaña, según se aprecia en los términos Collado y Cáscaros, en alusión a los montones de piedras que se ven en la ladera de la montaña.

En el término municipal de Casas de Millán (Cáceres) encontramos el topónimo $E l$ Mosque, entre la Sierra de Santa Marina y la Sierra de Zapatero, para el que se ha propuesto la misma etimología que para la antes citada oronimia leonesa del tipo Muesca, esto es, un derivado de *morsicam, del verbo latino morsicare, indicando una mordida o mordisco en el terreno, una hendidura o grieta. Estas hendiduras en el terreno solían 
emplearse como camino natural para pasar de una ladera a otra de un mismo monte, es decir, eran una especie de puertas naturales. Un dato interesante es que en la cartografía antigua este étimo El Mosque aparecía como El Bosque, lo que posiblemente se debe a una deformación popular del topónimo, convirtiendo la nasal bilabial en bilabial sonora, no sin una racionalización por parte del hablante, pues, por un lado, El Mosque está en una zona boscosa y, por otro, es tendencia del habla extremeña de la zona convertir las nasales bilabiales en bilabiales sonoras. En este sentido, el propio Sánchez Salor (1999: 134-135), hablando de estos topónimos y, más concretamente de la Sierra de la Mosca de Cáceres, cree posible relacionarlos con "bosque":

"Y es muy probable que estén en relación con el nombre común «bosque» topónimos como Mosqueruela, en Teruel; Mosqueiro y Mosqueiros en Pontevedra, Moscosa, en Salamanca. He traído a colación estos topónimos porque en Cáceres tenemos la Sierra de la Mosca; y no veo yo qué tiene que ver la mosca con una sierra; todo tiene más sentido si pensamos que Mosca es una deformación popular a partir de «bosca» o «boscaje»; parece, en efecto, tener más que ver con bosque que con el insecto conocido como mosca. Habría intervenido la etimología popular y la similitud fonética entre $m$ - y $b$ ".

Otra teoría, para explicar todos estos topónimos relacionado con las "moscas", es la expuesta por Román del Cerro (1990: 37), quien, a la hora de explicar topónimos alicantinos como Plana de la Mosquera, Moscón y Tossal de los Mosquitos, acude al ibérico Mosko-Moko, "pico, cima”. Se podría añadir el despoblado Mosquera también en Alicante, rodeado de varios cerros o "picos". Son zonas rocosas con numerosos picachos en piedra. Y es que, en efecto, en vasco existe el término mosko/ moko, con el significado de "pico de las aves" y con la acepción oronímica de "pico, altura, cumbre, punta, cima, morro, extremidad”. Hay además en dravídico una raíz *musk- con el mismo significado.

En Francia, siempre aludiendo a grandes cimas, hallamos diversos topónimos en los que se alternan las raíces Mouch-/ Mouss-/ Muss-, por ejemplo: Le Moucherotte, Le Moucherolle (cerca de Grenoble), el Mont Mouchet (Macizo Central), el Pic des Mouches (en el sustrato jurásico de la cadena de Aravis) y el caserío de Mussillon (Tarentaise). Parece que en todos estos casos hemos de descartar el origen entomológico y acudir a un tema prelatino *musk-, "roca", que ha sido atraído por el término latino musca, "mosca", para explicar así la evolución fonética irregular que han experimentado (Dauzat 1978: 175b). Asimismo, encontramos Le Mousquet (Plaisance), con un radical precéltico *musk-, que se encuentra en los nombres de roquedos, arrecifes y montañas. Esta misma raíz ha sido productiva en la oronimia francesa, pues tenemos el monte Mousqua, el pico más alto de la Margeride; y el pico Mousqua, cerca de Grèdre, en el departamento de los Hautes-Pyrénées, donde también se halla el Val de Mosquera; en los Pirineos-Orientales tenemos el Roc Mousquit; $\mathrm{y}$, en fin, el roquedo Malmouche, en el lecho del Ródano, y el promontorio rocoso Malmousque en el litoral marsellés. En los dos últimos casos, el primer elemento del compuesto toponímico contiene la base prerromana, posiblemente precéltica, *mal / *mel: "roca, monte", con lo que estaríamos ante una tautología muy habitual en toponimia. Y en Italia encontramos la Cima Mosca (2141m.), una montaña de los Alpes, en Trento, Italia nororiental, documentado en 1472 como Mons de la Musca in Valle Arsia (Battisti 1969: 171). 
Volviendo al topónimo del que partimos en nuestra investigación, la Sierra de la Mosca de Cáceres, pensamos, como antes expusimos, que lo más característico de la misma son los crestones rocosos que se aprecian vista la sierra desde los llanos. Y, si consideramos que en el extremo opuesto de nuestra sierra se halla El Risco de Sierra de Fuentes, un orónimo que expresa claramente las cualidades de "hendidura o corte" y "peñasco alto y escarpado" (D.R.A.E.) identificativas de toda la Sierra de la Mosca, creemos que, efectivamente, el significado de este orónimo podría relacionarse con muesca y con el verbo moscar, términos derivados del latín morsicare, "morder", y, por extensión, aludir a las "muescas, hendiduras o cortes de los altos y escarpados peñascos" que se aprecian en toda la sierra.

No obstante, teniendo en cuenta que, según demostramos recientemente (Mañas 2016), los hidrónimos Marco y Marimarco contenían la raíz prerromana *mar-/mor, "agua remansada", no podemos eludir la posibilidad de que en la Sierra de la Mosca estemos también ante una raíz antigua *mor-, concretamente prerromana y de carácter oronímico, con el significado de "montón de piedras", con el añadido del sufijo derivativo $-s k o /-s k a$, quizás celtibérico (Villar 1995: 142), con valor abundancial y aumentativo. El topónimo original bien pudo ser *Mor-ska, que por asimilación consonántica daría *Mosska> Mosca. La Sierra de la Mosca significaría, entonces, la "sierra de las piedras", una sierra "con muchos y grandes peñascos".

\section{Los puercos}

Hay en la toponimia española numerosos topónimos que parecen estar relacionados con el nombre común "puerco", pero que en muchos casos nada tienen que ver con el mamífero "cerdo". Vamos a partir de la denominación antigua de un pueblo cacereño, Arroyo del Puerco, para extender luego el análisis etimológico a otros topónimos similares de la geografía española y europea.

El actual municipio Arroyo de la Luz, está situado en los llanos de Cáceres y toma parte de su nombre de la corriente de agua que pasa por la población, el llamado Río Pontones. Su denominación antigua era Arroyo del Puerco, pero en diciembre de 1937 cambió su nombre, quizás por considerarse que el término "puerco" era poco digno para calificar al pueblo o porque en plena Guerra Civil se decidió más adecuado el componente religioso de la advocación mariana de Nuestra Señora de la Luz, a la que está dedicada una antigua ermita en la dehesa boyal de la Luz.

El nombre original de Arroyo del Puerco se ha venido atribuyendo tradicionalmente a la hipotética presencia de verracos de piedra de la época de los vetones (siglo V a. C.), muy habituales en las provincias de Cáceres, Salamanca, Zamora, Ávila, Toledo y Segovia, así como en las regiones portuguesas de Beira Interior Norte y Tras-os-Montes (Álvarez-Sanchís 2003: 286). Asimismo, se han aducido otros topónimos paralelos con la forma "puerca", como Puerca en Salamanca o Las Puercas en Castuera, que podrían aludir a los lomos de tierra que se forman a ambos lados de los surcos del arado, conectándolos así con el verbo "aporcar" (del latín $a d+$ porca), esto es, "remover la tierra para amontonarla en torno a los troncos o los tallos de cualquier planta" o "cubrir con tierra la simiente". ${ }^{3}$ También se ha pensado

Cf. Varrón, R. R. 1.29.3: Qua aratrum vomere lacunam striam fecit, sulcus vocatur. Quod est inter duos sulcos elata terra dicitur porca, quod ea seges frumentum porricit: "La raya profunda que deja la reja del arado al pasar 
que el étimo Arroyo del Puerco pudiera proceder de la presencia de jabalíes que acudían a beber y revolcarse en el mencionado río de la población, en cuyo caso estaría en conexión con el Regato del Puerco en Badajoz y el Arroyo del Puerco en Sevilla (Castaño 2004: 46-47).

Estos "puercos" toponímicos, ciertamente, podrían aludir tanto al cerdo doméstico como a los jabalíes y serían formas relacionadas con el latín porcus, "cerdo", del mismo modo que las formas "porqueros" o "porqueras" podrían tener que ver con el latín porcarius o porcaria, aludiendo a lugares donde se crían cerdos o se encaman los jabalíes. También cabría la posibilidad, menos verosímil, a nuestro juicio, de que estuviéramos ante antropónimos, pues Porcarius, Porcius o Porcianus son nombres romanos derivados de porcus, en cuyo caso se aludiría a un poseedor: "el arroyo de Porcio o de Porciano" (García 1993: 127-128).

No obstante, creemos que lo importante en esta clase de topónimos es que el étimo "puerco" o su correspondiente derivado van siempre acompañando a algún accidente geográfico de carácter oronímico o, sobre todo, hidronímico. Así, en León encontramos el Arroyo Valporqueras, afluente del Órbigo, Arroyo de Puente Porqueiro, Arroyo de Valdeporcas, Arroyo de Valdepuerca, Vallepuerco, Valle la Puerca, Porciles, El Porcayo, Fipuerco, Collado de Valporquero, Arroyo Porciso o el antiguo pueblo llamado Río de Porcos, en La Cabrera leonesa. En Zamora tenemos la localidad llamada Puercas, dependiente del municipio de Gallegos del Río, regado por los Arroyos de Pelayo y de la Raya. En Galicia también hay Ponte y Fonte do Porco y Arroyo de Pan Porco. En Francia nos encontramos con Valat du Porc, Rivière y Ruisseau de Pourcharesses, Valat de Pourquière, Ruisseau de Rieu Pourchier. En Huesca hallamos la Fuente del Puerco y La Canal del Puerco, una depresión de terreno ocasionada por las aguas del deshielo, donde la voz "canal", del latín canale, significa "cauce pequeño hecho en el suelo de un campo o prado para que circule el agua y evitar que se acumule en la parte baja de éste". Y es que ya en latín, según Festo (p. 244.6), "Se llaman porcae a los surcos más abiertos que se trazan, según se dice, para desviar el curso de las aguas, porque impiden (porcant), esto es, no permiten que el agua dañe los cultivos; pues los surcos más cerrados se denominan limi". ${ }^{4}$ Es decir, el término latino porca y la forma catalana medieval porcaria significan "canal de desagüe", el "surco que se abre en las tierras para que expulsen el agua sobrante y no se inunden".

Por tanto, la base Porc-, Puerc-, que es tan abundante en la toponimia aplicada a ríos o arroyos no parece que tenga que nada que ver con los puercos o jabalíes, ni tampoco con antropónimos romanos del tipo Porcius, como sostiene Galmés (2000: 67-68) para Porcuna (Jaén), que tiene también un Arroyo Salado de Porcuna. Hemos de remontarnos, seguramente, a una base hidronímica indoeuropea *prka, "reguero, surco" y también "barranco", ya señalada por Pokorny y propia del indoeuropeo occidental (García 1993: 129), la misma raíz de donde derivaría el término catalán rega $(<r i c a ̂)$ y de la que saldrían muchos topónimos que llevan las palabras

por la tierra, se llama surco, y la tierra elevada que queda entre dos surcos recibe el nombre de porca ("loma o caballón"), porque ella porricit (alza, levanta) la semilla del trigo". L. L. 5.39: ab eo quod aratri vomer sustulit, sulcus; quo ea terra iacta, id est proiecta, porca: "De aquello que la reja del arado levanta (sustulit) deriva el nombre de surco (sulcus); el lugar adonde esa tierra se echa, esto es, se extiende (porrecta), se denomina porca ("parte alta del surco")". Cf. Festo, p. 274.19.

$4 \quad$ Porcae appellantur rari sulci, qui ducuntur aquae derivandi gratia, dicti quod porcent, id est prohibent aquam frumentis nocere: nam crebiores sulci limi vocantur. 
Rey, Reina o Roy, seguramente deformaciones del céltico reku/reka> rego o rega, "surco, reguero, canal, riego", etc. (Llamazares 1993). El pueblo cacereño Monroy, cruzado por el Arroyo de Monroy, llevaría esa misma raíz hidronímica integrada en su topónimo: la primera parte, Mon-, es muy común en la toponimia ibérica para señalar un "monte" o "lugar elevado"; mientras que el segundo componente, -Roy, "surco, reguero", alude a la depresión ocasionada en el terreno por el curso de agua del mencionado arroyo.

Del mismo modo, en fin, el nombre antiguo de nuestro pueblo, Arroyo del Puer$c o$, no sería un zoónimo, sino un doble hidrónimo (arroyo + surco, reguero), aludiendo tautológicamente al Río Pontones que pasa a su vera. Otra cuestión, en la que no vamos a entrar, es si el hidrónimo Río Pontones procede del término latino ponto, pontonis, en español "pontón", con el significado de "puente formado por maderos o de una sola tabla" para atravesar el río, o si se trata de un hidrónimo falsamente transparente. El parecido con la raíz hidronímica indoeuropea * prka de donde procede nuestro Arroyo del Puerco podría darnos pie a suponer que lo que hoy en día es el Río Pontones bien podría haber sido antiguamente *Río Porcones o algo parecido y que por deformación popular ha acabado aludiendo a "puente".

\section{Los toros y las vacas}

Toril es un pueblo cacereño perteneciente a la comarca de Campo Arañuelo, se encuentra cerca de Plasencia y está rodeado de dehesas y praderas. El topónimo parece transparente y se han planteado dos posibilidades: que antiguamente su nombre fuera Torril (Corchón 1963: 192), en alusión a una supuesta torre musulmana emplazada sobre algunas ruinas romanas; o que el étimo en sí es de origen ganadero, similar al de majada, significando el recinto o "lugar para recogerse el ganado" (Castaño 2004: 325), motivado por sus múltiples dehesas y pastizales, en cuyo caso habría que partir del latín taurus, "toro".

Pero el número de posibilidades etimológicas no acaba aquí. También existe el término latino torus con el significado de "protuberancia", "parte elevada del terreno", y, visto que esta pequeña aldea se encuentra en una suave loma rodeada de dehesas y praderas, podría tomar su nombre de ahí. Asimismo, hay una raíz oronímica prerromana *Tor-, "montaña, montículo, cerro, prominencia de una ladera", que a veces se latiniza como taurus y que pervive en el catalán turó, "elevación moderada del terreno", y acaba dando topónimos leoneses como Toral, Turrón, La Turriera (monte) u Horcado Turonero (García 1993: 130-131). Este significado de "elevación moderada del terreno", como decimos, tampoco le viene mal al Toril cacereño. No obstante, hemos de tener en cuenta que junto al pueblo pasa el Arroyo de Toril, que presumiblemente es el que da nombre a la población, por lo que, a nuestro entender, hemos de estar ante un hidrónimo y no ante un orónimo. De hecho, existe una conocida raíz hidronímica prerromana *Ter-/*Tor-/*Tur-, "rápido, fuerte", con el significado original de "corriente de agua que baja de la montaña" impetuosamente. Estos hidrónimos de la serie *Tur-, estudiados por Villar (1995), son abundantes en la toponimia ibérica y, sólo en la provincia de León, García (1993: 131) recoge el Río Torío, Rio Turienzo, Arroyo de las Toradas, Arroyo de los Torales, Manantial del Toro, Arroyo de Toral, Arroyo Torizos, Río Toro y Valdetoro. Encontramos, tam- 
bién el Río Toril, afluente del Poqueria, en la Alpujarra granadina, dando lugar al Barranco del Toril; varios Arroyo Toril en Badajoz; Arroyo Toril en Jaén y Toledo; Barranco Toril en Murcia; Hoya Toril en Ávila; Regato de Toriles en Badajoz, etc. Y en Francia hallamos los ríos Taure y Taurion.

Creemos, pues, que el topónimo cacereño Toril es un hidrónimo, que toma su nombre del Arroyo de Toril, una corriente de agua más o menos impetuosa, dependiendo de las lluvias, que baja a desembocar en el Arroyo Porquerizo, que, como ya sabemos, nada tiene que ver con "puerco" ni con "jabalíes".

Lo mismo ocurriría con la localidad de Segura de Toro (Cáceres), situada en el Valle del Ambroz y cuyo origen se considera vetón porque se ha encontrado en el lugar la escultura de un toro en granito del siglo VI a. C. (López 1989: 97). El pueblo está situado en la ladera de los Montes de Tras la Sierra, su relieve es montañoso y cuenta con varios arroyos, entre los que destaca Garganta Ancha. Se ha supuesto que su topónimo es transparente y que su primer elemento, Segura, alude a la existencia de un castillo de carácter defensivo que los templarios construyeron en el siglo XII para vigilar la Vía de la Plata en la Reconquista, lo que le conferiría una situación de seguridad proporcionada por dicha fortaleza; en cuanto a su segundo componente, De Toro, se cree que se alude al verraco vetón encontrado en la localidad y ubicado en la plaza del pueblo (Castaño 2004).

No obstante, entendemos que estamos ante otro ejemplo de toponimia mítica y que su nombre encierra significados ocultos. En efecto, el primer elemento, $\mathrm{Se}$ gura, podría remontar a una raíz antigua indoeuropea con el significado de "hoz" o "guadaña", porque el arroyo Garganta Grande forma una hoz a su paso por la aldea, aunque más bien creemos que en la base del topónimo se encuentra un ligurismo, concretamente la raíz *sik-, *sek-, con el significado de "corriente de agua", un hidrónimo muy común, tanto en Francia como en España. En Francia tenemos el río Sequana> La Seine, el Sena (cf. en Asturias el arroyo Siguena, afluente del Se1la); *sik-ara, *sek-ara> Segre (Maine-et-Loire), Segrie (Barthe), Segrie Fontaine (Orne), Segogne (Cher), donde tenemos una tautología, pues ogne significa también "fuente, río". Con esta misma raíz nos encontramos en España el arroyo Siguena, Sigüeña (Asturias), Rioseco (Medina de Río Seco, Valladolid), el río Sequillo (que pasa por León, Palencia, Valladolid y Zamora), cuyos nombres no tienen nada que ver con un supuesto caudal escaso o una carencia de humedad, que sería algo contradictorio aplicado a un río, sino que están relacionados con la raíz hidronímica *sik-, *sek- que estamos comentando. Lo mismo debemos decir de los ríos españoles $\mathrm{Se}$ gre y Segura (Galmés 1996: 22). En cuanto al segundo componente, De Toro, igual que en el caso de Toril no tiene que ver con el macho bovino, tampoco en el caso de Segura de Toro tiene que ver con el verraco granítico. O bien nos encontramos con la raíz oronímica prerromana *Tor-, "montaña", pues el pueblo está situado en pleno monte, o bien tenemos la raíz hidronímica prerromana *Ter-/*Tor-, aludiendo a un torrente de agua "rápido y fuerte". Nos inclinamos por esta segunda propuesta y defendemos la idea de que el topónimo Segura de Toro contiene un doble hidrónimo con el significado de "corriente de agua" que baja de la sierra "rápida e impetuosamente", como ocurre en realidad con las aguas que corren por estas gargantas del Valle del Ambroz.

Y si ni Toril ni Segura de Toro guardan relación toponímica con el toro, tampoco el topónimo Tornavacas tiene nada que ver con la hembra del toro. En la interpretación del topónimo creemos que se ha errado sistemáticamente. Por un lado, pertene- 
ce al terreno de la leyenda y de la fábula la explicación tradicional que hace remontar el topónimo a la Reconquista y a la lucha con los musulmanes. Efectivamente, se cuenta que el Conde Fernán González llegó en su lucha con los moros a Tornavacas y que allí colocó unas teas encendidas en los cuernos de las vacas, las cuales arremetieron contra los enemigos, los aterraron, los pusieron en fuga y luego ellas tornaron a su querencia. Otra versión del mito, narrada por Flores del Manzano (1998: 252-253), pone por protagonista al rey cristiano Ramiro II, quien, ayudado por unos pastores, urdió la estratagema de las vacas con teas ardientes en sus cuernos y, tras ver el éxito de su engaño a los musulmanes, ordenó "Torna-Vacas". No parece que sirvan de prueba a estas interpretaciones ni una supuesta inscripción latina encontrada en el siglo XVIII y ya desaparecida que decía "Mi resplandor aterró a las turbas de moros y sarracenos y los hizo huir" (Mea illuminatio terruit turbas maurorum sarracenorumque fugere fecit) (Flores 1998: 253); ni tampoco el escudo con dos vacas llevando en sus cuernos teas encendidas, pues el escudo se aprobó en el año 1991 y, por tanto, es moderno. Estas explicaciones, como advierte Castaño (2004: 326), son claros ejemplos de etimología popular y parecen tomados de la Biblia, donde Gedeón orquesta un plan astuto para atacar por sorpresa a los madianitas llevando cántaros vacíos con teas ardiendo dentro de dichos cántaros (Jue. 7.15-18). Tampoco nos parecen aceptables las explicaciones que conectan el topónimo con la ganadería, en el sentido de que el Puerto de Tornavacas es un paso importante entre Castilla y Extremadura y por él pasaría el ganado; o que el étimo tenga que ver con el latín tornare, "devolver algo a quien lo poseía", en referencia a una "prestación entre dos" $\mathrm{y}$ al servicio que a alguien le ha prestado una vaca y, tras ello, se la devuelve o torna a su legítimo propietario, guardando ambos agricultores una mutua colaboración para compartir las vacas en el cuidado y labranza del terreno (Castaño 2004: 327).

Tornavacas no es un topónimo único. Encontramos Torna-Vaquinhas en el Alentejo portugués, un Tornabous en Lérida, un Tornabusia en Burgos y, lo más importante para nosotros, los accidentes geográficos llamados Tornavacas en León y Trastornavacas en Zamora, así como el Arroyo de Tornavacas en Córdoba. Ello nos hace pensar que en nuestro nombre Tornavacas ha de haber componentes hidronímicos, especialmente cuando el río Jerte, que vertebra toda la comarca, nace en las cercanías del pueblo y además, a poca distancia de su nacimiento, pasa por el mismo Tornavacas. El topónimo, pues, tiene que ver con el agua y debe dividirse en dos elementos hidronímicos: Torna-Vacas.

En cuanto al primer componente, está estudiado que los topónimos Torna, Torno y Retorno son de origen prerromano, con un significado de "chorro de agua" probablemente derivados de la raíz hidronímica prerromana *ter-/ *tor-/*tur, "frotar, atravesar", con sufijo -na- (-no-) (Villar 1995: 235), similar a la antes vista raíz *ter-/*tor-, "rápido, impetuoso", muy adecuada a nuestro topónimo, porque en Tornavacas las aguas bajan rápidas e impetuosas, sobre todo en época de deshielo, y además atraviesan el pueblo. El mismo origen tiene también el topónimo El Torno, población del mismo Valle del Jerte, en cuyas inmediaciones hay numerosas gargantas y arroyuelos, pasando junto al pueblo las caudalosas aguas de la Garganta de la Hoya de las Canales.

El segundo componente es también hidronímico y hemos de partir de la raíz indoeuropea *wak-, procedente de la base *wek-, *wok-, "curvo, que se tuerce", que ha dado lugar a abundantes hidrónimos (Ouákou, Vaca, Vacas, Vókè, Vókpievè, *Wokalo-, Vacalus, Wacbach, etc.), así que los ríos denominados Vaca(s) serían eti- 
mológicamente ríos curvos, que trazan pronunciadas curvas o que tienen meandros (Villar-Prósper 2005: 76), como realmente es el río Jerte a su paso por Tornavacas, trazando una pronunciada curva antes de entrar en el pueblo.

Tenemos, en este sentido, un Arroyo de la Vaca (*waka) en la provincia de Badajoz que, tautológicamente, significa "arroyo de aguas sinuosas", pues presenta curvas pronunciadas, y se encuentra junto a la localidad pacense de Cabeza la Vaca, donde vemos unidos un elemento oronímico: Cabeza, "cabezo, monte, prominencia del terreno" y un componente claramente hidronímico: La Vaca, "corriente sinuosa de aguas", cuyo significado en conjunto sería el de pueblo situado en una loma y junto a un arroyo de curvas pronunciadas.

\section{Las cabras}

Otro pueblo jerteño es Cabrero (Cáceres) y se ha dicho que estos topónimos formados sobre las bases "cabra, "cabrera" y "cabrero" son transparentes y aluden evidentemente a la existencia de cabras, aplicándose a tierras pedregosas, aptas para dicho animal. Incluso se apunta que, como en el Interrogatorio de la Real Audiencia se denomina a la localidad Casas del Cabrero, puede tratarse de un antropónimo y hacerse referencia a una persona con el oficio o el apodo de "cabrero" (Castaño 2004: 79). El escudo heráldico de la población, también de época moderna (aprobado en 2004), recoge erróneamente "cinco cabras de oro, acornadas de púrpura".

Nada más lejos de la realidad. Aunque es verdad que casi toda la comarca del Jerte se ha dedicado tradicionalmente a la ganadería de la cabra, encontramos numerosa toponimia ibérica con el mismo radical y que no necesariamente son pueblos cabreros: Cabra (Córdoba), Cabra de Mora (Teruel), Cabra de Camp (Tarragona), Cabra del Santo Cristo (Jaén), Cabral (Vigo), Cabredo (Navarra), Cabrega (Navarra), Cabreira (Pontevedra), Cabreiroa (Orense), Cabreiros (Lugo), Cabrejas del Campo y del Pinar (Soria), Cabrera de Almanza (León), Cabrera del Mar, que aparece en documentación antigua del siglo X citada como Cabraria (Barcelona), próxima al Mont Cabrer, Cabreriza (Soria), Cabrerizos (Salamanca), Cabreros del Monte (Valladolid), Cabreros del Río (León), Cabretón (La Rioja), Cabria (Palencia), Cabrianes (Barcelona), Cabrillanes (León), Cabrillas (Salamanca), Cabrils (Barcelona), Cabrita (Jaén) o Cabrojo (Cantabria). Como en el topónimo Cabrero del Valle del Jerte, parece que nos encontramos ante el radical *Cabar-, *Cabr-, *Cabur-, relacionado con el indoeuropeo *Kapro, "cabra", a través del latín capra. Lo llamativo es que en muchos de estos lugares mencionados la explotación ganadera de la cabra no ha sido significativa. Por ello, Galmés (1990: 33) relaciona estos topónimos con la raíz *kar, *karabo, que en castellano ha dado carba o carbera, transformándose por etimología popular en Cabra, Cabrera o Cabrero. Pero también pueden explicarse estos topónimos, como sugiere García (1993: 126) por la raíz prerromana * Kab-, "altura", o por Karpa, Karb, Crapa, Crepa, raíces oronímicas presentes en Malacabra (León) o en los topónimos franceses Cabrimont y Malacabrière, donde hallamos dobletes tautológicos (Fabre 1980).

Nosotros, en efecto, dada la altura del poblado, asentado en una montaña abrupta y escalonada gracias a los bancales trabajados durante siglos, creemos que hemos de partir de la raíz prehispánica *carabo-, "barranco, precipicio o lugar pedrego- 
so", cuyo origen estaría en la raíz indoeuropea *kr-, "duro", que se encuentra en el griego kratós ("poder") y en una raíz prehispánica *kar, *car-, *quer-, "duro", "piedra". Con sufijación obtenemos la base *car-alt-, de donde salen topónimos como Caralt, Cavall, Caballo; la base *car-a-, "pedregoso", se encuentra en topónimos como Caracol (<*kara collem, "colina pedregosa"), Caracolera, Carava, Caravaca, Caravia, Carabias, Carabanchel, Caravantes, Carabasot, Carabassí, Carabasí, Calabazas, Calabaceros...; y la base *car-abo, que es la que nos interesa ahora, da topónimos como Caraba y Carabaña (Galmés 1990: 31-32). Esta raíz *car-abopuede evolucionar a *carb-, por síncopa de la vocal -a-, y a *cabra-, por síncopa de la vocal $-a$ - e intercambio de consonantes, dando lugar, por asociaciones etimológicas, a topónimos como El Carbo (Castellón) y Carbonera (Palencia, Soria, La Rioja) o a un montón de pueblos de nombre Cabra, donde ni se alude al carbón ni a las cabras. Con esta raíz, añadiéndole el sufijo -ero, tendríamos que el topónimo Cabrero significa "pueblo situado en un lugar elevado, en un barranco o precipicio y en suelo duro y pedregoso".

\section{Los gatos}

Otro zoónimo aparentemente transparente lo encontramos en la población norteña de Gata (Cáceres), el mismo topónimo que sirve para dar nombre a toda la Sierra de Gata. Resulta evidente que el nombre no puede aludir a la presencia de gatos monteses, máxime cuando se repite en la toponimia extremeña como Sierra del Gato (Monterrubio), Peñas del Gato (Quintana de la Serena) o Huerta de Gata (Zalamea) (Castaño 2004: 148); y también en el ámbito ibérico es muy abundante, por ejemplo, La Gata (Ávila y León), Loma de la Gata (Teruel), Peña de la Gata (Segovia), Cabo de Gata (Almería), Cerro Gata (Jaén), Sierra de la Gata (Ciudad Real), Cerro de la Gata y de las Gatas (Ciudad Real y Cuenca), etc.

Las propuestas etimológicas han sido variadas, desde quienes, como Nieto Ballester, lo consideran un latinismo derivado de fonte capta/u, "fuente hallada, encontrada, encauzada" (Nieto 2000: 401), asociando nuestro topónimo con otros del tipo Cañadas de Fuentes Cautas (Toledo), Zancorta (Álava), Fangato (Huesca), Fuente del Cauto (Ciudad Real), Fuente de la Antecada (Guadalajara), Lagata (Zaragoza) o Gata de Gorgo (Alicante); hasta quienes, como Llorente Maldonado, lo consideran un topónimo preindoeuropeo (Llorente 2003: 100). Sánchez Salor (1999), por su lado, considera que Gata, nuestra sierra y pueblo, no guarda relación con el conocido animal doméstico y, rechazando que tenga que ver con Santa Ágatha, "Santa Águeda", recuerda que gat- es una raíz prerromana muy prolífica en toponimia, que sirve para designar cuevas y oquedades, es decir, rocas erosionadas y agujereadas, y que en España la etimología popular ha confundido con el animal "gato"; asimismo en los Alpes tenemos Le Gateau y Le Gat, que son montes con abundantes oquedades (Sánchez Salor 1999: 119).

Nosotros, teniendo en cuenta que el topónimo es abundante en toda la península y que casi siempre alude a elevaciones del tipo "sierra", "peña", "cerro" o "loma", creemos que el nombre Gata, procedente de un anterior *Cata, vendría de la raíz prerromana *k-t-t, con las bases alternantes *kat(t)-/*kot(t)-, para las que Rivas Quintas (1994) señala el significado de "punta, muñón, prominencia". Se trata 
de un topónimo muy adecuado para la población de Gata, ubicada en un alto, en la falda sur de las Jañonas (1367 metros), para el propio río que la atraviesa, la Rivera de Gata, una corriente de agua que transcurre por entre valles encajonados rodeados de altos montes hasta desembocar en el río Árrago y, en fin, para toda la comarca de la Sierra de Gata, cuyo relieve es muy accidentado y tiene puntos elevados como el Monte Jálama (1492 m.), el Pico Jañona (1367 m.), la Sierra de las Mezas (1265 m.), La Nave (1279 m.) o La Bolla (1519 m.).

\section{Los lobos}

La toponimia mítica también ha confundido la raíz hidronímica preindoeuropea *lup-/*lub- de origen mediterráneo con la raíz latina del sustantivo lupus, "lobo", y así los hablantes de la época de la dominación romana asociaron por homofonía los topónimos que significaban "fuente, agua" con el conocido animal "lobo" (<lupum). Explicar hidrónimos como Riolobos (Cáceres y Salamanca), Guadiloba y Guadalupe (Cáceres), Guadalope (Teruel) o los abundantes accidentes geográficos hispanos llamados Cantalobos (también presentes en Cáceres y Badajoz) atribuyéndoles relación con el lobo, justificándolos por ser lugares donde moraba el lobo, por habitar en dichos ríos la divinidad epónima Lobo, por sonar las aguas de estos ríos, metafóricamente, como el aullido del lobo o relacionarlos con el latín lupa, "loba", en el sentido metafórico de, según el D.R.A.E., "lomo [de tierra] no removido por el arado, entre surco y surco", es un error (García 1993: 126).

Lo más cabal es relacionar estos topónimos con la raíz hidronímica *lup-, *luba, *lupia, perteneciente al grupo lingüístico mediterráneo occidental, que ha dado lugar a una serie de nombres de ríos que, como decimos, se han asimilado etimológicamente con el cuadrúpedo "lobo". Cortés cita los siguientes ríos europeos: Lubien (río de Polonia), Luba (Lituania), Lubazowska (Polonia), Lupja (Rusia), Lubiesca (Silesia), Lupcsanka (Eslovenia), Lubina (Chequia), La Loubliére (Francia, afluente del Cher), Lupow (Pomerania), Lubochna (Eslovaquia), Lobán (Rusia), Lob (Rusia), Luban (Letonia), Lobe (lago y río de Letonia) (Cortés 1954: 28-29). Y Galmés (1996: 22-23) cita los hidrónimos españoles Fuente'l Lobo (Castellón), tautología que confirma el valor hidronímico del segundo componente, Barranco Lobo (Aragón), Lop y Lopera (Huesca), Ruiloba (Santander), antiguamente Río de Loba, Lobera (Castellón, Ávila, Palencia), Lobera de Onsella (Zaragoza), Llovio y Llobéu (Asturias), Lubián (Zamora), Lubierre (Jaca), Lobeira (Coruña y Lugo), Llobregos (afluente del Sagre), Llobregat (río de Barcelona), Guadalupe y Guadiloba (Cáceres), Guadalope (río de la provincia de Teruel), ríos éstos con el primer elemento guad- en árabe y, por tanto, tautológicos (Casillas 2007). También señala Sánchez Salor que la raíz *lup - es la misma raíz que aparece en el río Lupia, hoy Lippe, en Alemania; y está también en los ríos franceses Louve, Loup, cuyos nombres se consideran como célticos; y en el segundo elemento del pueblo cacereño Guada-lupe. Guadalupe, pues, sería un doble hidrónimo y significaría "río de fuentes", y no un zootopónimo que aluda a "río de lobos", ni tampoco un antropónimo que remita a "río de Ibn Lubb", que sería un guerrero camarada y correligionario de Ibn Marwan, bravo muladí alzado en armas contra el poder omeya y fundador de Badajoz, mediado el siglo IX; el Guadalupe de Extremadura, señala Sánchez Salor (1999: 119), podría explicarse en 
último término remitiendo a este personaje; pero no, por ejemplo, el río Guadalope de Alcañiz, que quedaría muy lejos del bravo muladí. Si la raíz de -lupe es la que está en conexión con un concepto acuático, Guadiloba, Lobosilla y Lebosilla, Guadalobón, Lubierre y Ríolobos podrían explicarse, por etimología popular, a partir de la misma raíz. Es habitual que un formante hidronímico termine por convertirse, en virtud de una deformación popular, en el nombre de un animal.

Pero también tenemos la raíz *lup-/*lob- con valor oronímico y podemos encontrar los componentes lobo y loba aplicados a montes, cerros, picos, collados, peñas, piedras o valles. Así se explicarían topónimos franceses como Massif de la Loube, Mont de Louberon y la Loubo, nombre de una montaña. En territorio español son también muy abundantes y García (1993: 127) ofrece una buena nómina sólo para la provincia de León. Asimismo, también en Francia tenemos topónimos como Chanteloup y en España muchos accidentes geográficos denominados Cantalobos. Evidentemente, no se está aludiendo al aullido de los lobos, sino que estamos ante un elemento celta indoeuropeo *kanto/-a que presenta frecuentemente el valor de "piedra, roca" o "montaña, altura". Así tenemos compuestos como Chantepierre o Chanteroc, que podrían ser tautológicos, igual que en español Cantalapiedra (Salamanca), o el Puerto de La Canda (Zamora-Orense) y Candamo (Asturias) con sonorización de la dental. También señala Galmés (2000: 147) Cantagallo (Salamanca), Canta-el-Gallo (Toledo, Badajoz y Lugo), Gallocanta (Zaragoza y Caste1lón), Cantalarrana (La Coruña, Lugo y Pontevedra), Cantarranas (Salamanca) y, en fin, Cantalobos (Huesca, Zaragoza y Castellón) o Cantallops (Gerona), donde, si no cantan las piedras ni los gallos ni las ranas, tampoco cantan los lobos. Posiblemente, estos Cantalobos ( $<* k a n t a+* l u b-)$ están refiriéndose a alturas rocosas abundantes en aguas o, tautológicamente, a montañas rocosas.

\section{Conclusiones}

Hemos analizado etimológicamente numerosos nombres de lugar de la provincia de Cáceres que se repiten de forma exacta o parecida en el resto de la geografía española y que incluso encuentran correspondencia con otros topónimos europeos, especialmente franceses. Todos los nombres examinados se presentan en apariencia como zoónimos transparentes, si bien sus auténticas etimologías resultan más oscuras y remontan casi siempre a raíces muy antiguas de origen prerromano.

Así pues, aunque estos zootopónimos parecen guardar relación con distintos animales muy conocidos en el ámbito español, tales como moscas, puercos, toros, vacas, cabras, gatos y lobos, creemos haber demostrado que la asimilación de tales nombres de lugar a estos conocidos animales se debe, en la mayoría de los casos, a deformaciones y etimologías populares y que, por tanto, dichos étimos nada tienen que ver ni con los insectos, ni con los gorrinos, ni con el ganado vacuno o caprino, ni con los felinos, ni con los lobos. Efectivamente, cuando hay orónimos que llevan el término mosca, muchas veces podemos estar ante una raíz prerromana *mor: "montón de piedras"; si hallamos topónimos relacionados con el término puerco, es posible que tengamos que relacionarlos con la raíz hidronímica indoeuropea *prka: "reguero, surco"; respecto a pueblos en cuya denominación aparece el nombre toro o alguno de sus derivados quizás debamos pensar en una raíz hidronímica prerromana 
*tor-: "rápido, fuerte" y no en el macho bovino; de igual manera, muchos topónimos que parecen hermanados con la hembra del toro lo que realmente encubren es la raíz indoeuropea *wak-: "curvo, que se tuerce"; en otras ocasiones, cuando la referencia toponímica parece conectada con las cabras, lo que verdaderamente subyace es la raíz prehispánica *carabo: "barranco, precipicio"; finalmente, si el étimo alude a los gatos, no es raro que se encuentre oculta la raíz oronímica prerromana $* k$-t-t: "punta, prominencia", del mismo modo que, cuando ríos y arroyos llevan nombres alusivos a lobos, seguramente hallamos velada la raíz hidronímica preindoeuropea *lup-/*lub-: "fuente, agua".

Y es que con el paso del tiempo, con la evolución de las lenguas, con la etimología popular y mítica y, en fin, con alguna ayuda de los copistas, muchos topónimos se han deformado y asimilado a realidades cotidianas de nuestro entorno, si bien su auténtico significado no guarda relación alguna con el sentido que actualmente se les da.

\section{Referencias bibliográficas}

Álvarez-Sanchís, Jesús R. (2003): Los Vettones. Madrid: Real Academia de la Historia.

Battisti, Carlo (1969): I nomi locali del Roveretano distribuiti per comuni. Firenze: Olschki ed.

Canto Alicia Ma (1999): "Una nueva imagen de Ptolomeo: hipótesis de ubicación de ciudades vasconas", in Pueblos, lenguas y escrituras en la Hispania Prerromana, Francisco Villar y Francisco Beltrán (eds.), pp. 339-358. Salamanca: Ediciones Universidad.

Casillas Antúnez, Francisco José (2007): "Riolobos, un caso de más de tautotoponimia". Revista de Estudios Extremeños 63: 663-667.

Castaño Fernández, Antonio M. (2004): Los nombres de Extremadura. Estudios de toponimia extremeña. Mérida: Editora Regional de Extremadura.

Corchón García (J. (1963): El Campo Arañuelo: estudio geográfico de una comarca extremeña. Madrid: Ministerio de Educación Nacional.

Cortés y Vázquez, Luis L. (1954): El dialecto galaico-portugués hablado en Lubián (Zamora). (Toponimia, textos y vocabulario). Salamanca: Universidad de Salamanca.

Dauzat, Albert, Deslandes, Gaston y Rostaing, Charles (1978): Dictionnaire étymologique des noms de rivières et de montagnes en France. Klincksieck: Paris.

Fabre, Paul (1980): L'affluence hydronymique de la rive droite du Rhône. Essai du microhydronymie. Montpellier: Centre d'Études Occitanes.

Galmés de Fuentes Álvaro (1987): "Toponimia asturiana y asociación etimológica”, in Actes de les Xornaes de Toponimia Asturiana, Uviéu, pp. 31-39. Academia de la Llingua Asturiana.

Galmés de Fuentes, Álvaro (2000): Los topónimos: sus blasones y trofeos (la toponimia mítica). Madrid: Real Academia de la Historia.

García Arias Xose Lluis (2010): Toponimia de Teberga. Uvieu: Academia de la Llingua Asturiana.

García Martínez, Francisco Javier (1993): "Etimología e interpretación popular en los pueblos de León (II)". Lletres Asturianes: Bolentín Oficial de l'Academia de la Llingua Asturiana 47: 125-133.

Llamazares San Juan, Ángel (1993): “Rey, Reina y términos conexos en la toponimia leone- 
sa". Lletres Asturianes: Boletín Oficial de l'Academia de la Llingua Asturiana 49: 115129.

Llorente Maldonado de Guevara, Antonio (2003): Toponimia salmantina. Salamanca: Diputación de Salamanca.

López Monteagudo, Guadalupe (1989): Esculturas zoomorfas celtas de la Península Ibérica. Madrid: CSIC.

Mañas Núñez, Manuel (2016): “Sobre los hidrónimos Marco y Marimarco de Cáceres”. Anuario de Estudios Filológicos, XXXIX: 343-347.

Martín Bravo, Ana Ma (1999): Los orígenes de la Lusitania. El I milenio a. C. en la Alta Extremadura. Madrid: Real Academia de la Historia.

Nieto Ballester, Emilio (2000): "La toponimia de las fuentes en España: una nota sobre algunos resultados del lat. fonte". RFE, LXXX, 3-4: 395-406.

Pokorny, Julius (1959-1969): Indogermanisches etymologisches Wörterbuch. Bern: Francke.

Román del Cerro Juan Luis (1990): El desciframiento de la lengua ibérica en «La ofrenda de los pueblos». Valencia: Ed. Aguaclara.

Sánchez Salor, Eustaquio (1999): "Extremadura y los nombres de sus lugares". Boletín de la Real Academia de Extremadura de las Letras y de las Artes, X: 105-144.

Sánchez Salor, Eustaquio (2016): Nec mora nec requies. Selección de artículos al cuidado de Pedro Juan Galán, María Luisa Harto y Manuel Mañas. Cáceres, Universidad de Extremadura.

Villar, Francisco (2000): Indoeuropeos y no indoeuropeos en la Hispania prerromana. Salamanca: Universidad de Salamanca.

Villar, Francisco, Prósper, Blanca M $\mathrm{M}^{\mathrm{a}}$ (2005): Vascos, Celtas e Indoeuropeos. Genes y Lenguas. Salamanca: Universidad de Salamanca.

Villar, Francisco, Prósper, Blanca Ma , Jordán, Carlos y Fernández Álvarez, Mª Pilar (2011): Lenguas, genes y culturas en la prehistoria de Europa y Asia Occidental. Salamanca: Universidad de Salamanca. 